\title{
MR. HUTCHINSON'S "CHEIRO-POMPHOLYX."
}

By TILBURY FOX, M.D., F.R.C.P.,

PHYSICIAN TO THE SKIN DEPARTMENT OF UNIVERSITY COLLEG HOSPITAL, ETC.

Mr. Hutchinson, in the fasciculus of his " Illustrations of Clinical Surgery," just issued (April), has depicted and described a disease to which he has given the name "Cheiropompholyx." I have read his account of this form of erup. tion with no little astonishment; because, in the first place, the disease is nothing more nor less than that which $I$ described three or four years ago, in the third edition of my work on Skin Diseases, as "Dysidrosis"; and, in the second place, on more than one occasion it has been pointed out to Mr. Hutchinson that his projected Cheiro-pompholyx was my Dysidrosis (which has been long recognised at University College), and I possess a letter of his (dated Dec. 1873) in which he states his intention to "read your papers"; and, in the third place, his illustration is taken from a case which I saw at the suggestion of Dr. Russell Reynolds, and which, in conversation with Mr. Hutchinson, I declared to be a severe form of my Dysidrosis.

But, to make the identity of the two things clear, I will gut side by side Mr. Hutchinson's description of April, 1876, and my description of Jan. 1873 (Skin Diseases), concerning the main characters of the disease. The italics are mine.

Mr. Hutchinson's Description.

s The patient whose hands are here shown is a lady of about fifty years of age, single, who has been subject from the age of twenty onwards to a great variety of ailments, which have chiefly had reference to her nervous system.

"In several of the most severe cases which I have witnessed the eruption was attended by extreme depression of spirits, and in one this condition had been such as to lead the parents to fear insanity.

"There can be no doubt, I think, that this eruption is a neurosis, its tendency to spontaneous cure, and its frequent coincidence with other nervo ous symptoms, being of considerable weight in that dizection."

"Miss G- stated that she usually experienced, as premonitory symptoms, a general sense of increased discomfort, as burning of the hands and feet; next, with great burning and itching and a sense of stiffness, a number of deeply placed little blebs would show themselves by the sides of the fingers ; in a few days these would coal. esce, and enormous bullæ, such as those shown in the portrait, would result.

"It (Cheiro-Pompholyx) is rather a very severe examplo of what in minor degrees is tolerably common. Many, indeed, perhaps, most of us, are liable at times, in connexion with slight derangements of health, or possibly with exposure to the sun, to the
Dr. Trubury Fox's Description.

"I never knew any patient who had this disease, I am now describing, well. In all the severer cases patients have been the subject of great nervous debility, and in some cases have been under the care of physicians for various anomalous nervous diseasesodd muscular affections. Some have been prostrated by mental anxiety or worry. It may with probability be supposed that the innervation of the gland (sweat) is specially at fault."

"There is always muoh itching and a good deal of burning present with the eruption. . The hand is very stiff and painful. In its slightest form it is confined to the hand, occurring in the interdigits, over the palm, and along the sides of the fingers and on the palmar surface, some or all of these parts.

"The eruption is made up in the first instance of minute vesieles deeply imbedded in the skin. The vesicles are at firm isolated. They do not readily burst, and when they have existed for a few days the appearance of the affect.d part is just as though a num ber of small boiled sago-grains were imbedded in the skin These sago-grain-looking occurrence of a very irritable sago-grain eruption on the sides of the fingers. The socalled sago-grains are deeply placed effusions of serum, but in a large majority of cases they undergo spontaneous absorption after a few days, and not even peeling of the epidermis results.

More severe cases, in which the vesicles coalesce and develop into bullæ, are not very uncommon."

"With the bullous eruption on the hands there usually occurred a red lichenous rash over the whole body, which varied much in colour at different parts of the day, and which, although it never caused vesicles, was always followed by desquamation. .. While in a few of the most severe of all it is attended by a general red lichen rash

" Yet its duration is by no means always so short as in the case just narrated, and in some instances it may last for a couple of months, and require treatment."

"In her case the vesications always broke, and a state much resembling that known as psoriasis palmaris resulted in the palms, while on the sides of the fingers it looks more like eczema."

"The feet were always affected by it in a slight degree . . . and only in the more severe cases affects the feet."

"They (the sago grains) never by any chance result in eczema."

Can anyone doubt, after comparing the above quotations, and especially those containing the very peculiar expression, sago-grain-like, applied to the early stage of the eruption by myself in the first instance, that cheiro-pompholyx is dysidrosis? I cannot conceive why Mr. Hutchinson has ignored ruy account of the disease, as his attention has been specially directed to the identity of these two conditions. There are, however, two features of the disease which $\mathrm{Mr}$. Hutchinson fails to recognise-viz, the origin of the eruprion in the sweat apparatus, the vesicles being formed, not, as he asserts, by effasion of serum, but by collections of sweat; and the nature of the general rasb, which is miliary in character and not lichenous-two points upon which I have laid particular stress in $m y$ account of the disease. Fis designation is a most unhappy one. Mr. Hutchinson distinctly states that in his use of the term pompholyx he does not mean to imply that it has any relation to true pemphigus, the use of which term by him is therefore very misleading. It will be observed that he states that the disense attacks, not the hands only, but the feet also-a fact I previously put forward, and which renders his prefix cheiro an unfaithful one.

The disease was first distinctly described by myself in 1873 as an eruption occurring in subjects of nervous debility and trouble, especially about the hands and feet, though sometimes accompanied by a miliary rash; as consequent upon a paresis of the nerve-supply of the sweat apparatus, whereby its functions become deranged, with the consequent production of sago-grain-like vesicles, that soon aggregate together into bullie of small or large size, the disease having no relation to eczema, though it sometimes leaves behind it a reddened, scaly, slightly infiltrated derma. I do not deem it right to myself or to the school to withhold 
these comments, in the face of Mr. Hutchinson's assertion that he "is' not sure that any correct clinical description (of the disease) has been given."

Harley-street.

\section{CASES OF A URAL POLYPI.}

By G. P. FIELD, M.R.C.S., AURAL SURGEON TO ST. MARY'S HOSPITAL.

CASE 1.-A girl, A. M-, aged twenty-six, was brought to me at the hospital with most extensive disease of the mastoid cells. She had had a polypus removed somewhere in the country, about a year previously; no after-treatment had been adopted, and the discharge was allowed to con. tinue until the inflammation thus set up extended to the brain, and she nearly lost her life in consequence. A free incision over the mastoid process down to the bone considerably relieved her, and by careful treatment for six months, by astringent lotions \&c., keeping the parts constantly clean, she entirely lost the discharge, and regained a very fair amount of hearing power. This case shows what mischief may result from neglecting proper treatment after the polypus has been removed.

CASE 2-A lady was sent to consult me by Mr. Mi!son, in June, 1874. The right membrana tympani was perforated, and a small red polypus could easily be distinguished making its way through that structure. She had suffered from an offensive discharge from that ear for eight weeks, with slight pain and tinnitus aurium. The ear was syringed frequently with warm water, and afterwards a warm solution of carbolic acid and sulphate of zinc; five grains of each to one ounce was ordered to be poured into the ear, and allowed to remain for some time. The polypus was painted every morning with a solution of nitrate of silver, twenty grains to the ounce. After a very short time the discharge and the polypus disappeared, the membrane healed up, and the patient regained her hearing.

This case shows very well how smaller growths may be made to disappear by the constant application of caustics. Strong solution of sulphate of zinc answers very well in some of the softer kinds of polypus; or a combination of the two, as used in this case, is perhaps the best treatment.

CASE 3.-E. W-Z, aged forty-two, came to see me at the hospital with a large polypus completely blocking up the left external meatus. Says that she "has been deaf for three or four months, and has had slight noises in the head, but no pain. There is a great deal of very offensive discharge which comes away at times." The growth, which proved to be a very large one, I removed. Very slight hæmorrhage followed, and she was completely cured by using the sulphate of zinc and carbolic acid lotion, as in the last case.

CASE 4.-A. I-, aged sixteen, came to the hospital December 6th, with a large polypus in the right ear. It was easily removed, but left a large perforation in the membrana tympani. She attended regularly for two months. The discharge continued for some time. All kinds of lotion were used; the acetate of lead, two grains to the ounce, proved of most service. At length the discharge ceased, the perforation became much smaller, and she left the hospital hearing perfectly well.

CASE 5.-This was a young man sent to see me by Mr. Ransford. Much the same kind of polypus as in last case a very large one. The hæmorrhage after the operation was severe, but was checked after a little time by syringing cold water gently into the ear. The perforation in the membrane healed up remarkably soon. In ten days' time he was quite well. The carbolic acid and sulphate of zinc lotion was used diligently in this case.

CASE 6.-J. MI-, aged thirty-two, a school teacher, came to the hospital with a large polypus in each ear. They were both successfully removed with Wilde's snare. great quantity of discharge came away afterwards, which readily yielded to the frequent application of astringent lotions. She was going on very satisfactorily when she left the hospital.

I could give a great many instances of the same kind; but what I want especially to point out is, that a successful termination to these cases is not to be expected unless a careful treatment is adopted after the removal of the polypus. If the discharge is allowed to go on unchecked after the operation, the disease will in all probability shortly return. Polypi are frequently removed, and no steps are taken to get rid of the accumulated secretion in the tympanic cavity, and, therefore, in a short time another polypus is likely to spring up again. Thorough cleanliness is most essential. Hinton remark: "Growths of this nature in the ear are extremely prone to recur, but the degree of obstinacy with which they resist treatment is very variable. In some rare cases they will come away spontaneously and leave a per. manently healthy surface; in others they will disappear before treatment, and show no tendency to recur; in others their eradication is attended with the utmost difficulty. It has seemed to me that the accumulation of secretion behind the polypus or its root is one of the most frequent sources of difficulty in their treatment, especially in cases where the membrana tympani is perforated. The viscid matter poured out by the spongy mucous membrane of the tympanum tends to cling about its various crevices and maintain a perpetual irritation which sets every kind of caustic or healing application at defiance. Accordingly, a chief object to be aimed at in the management of polypi is the perfect cleansing of the deep-seated parts of the organ. This is not to be effected by syringing merely, however vigorous and long-continued. Water does not remove the tenacious matter, nor, probably, does the stream reach the whole secreting surface."

I have found, almost invariably, that aural polypi arise from the mucous membrane of the tympanum, and not from the walls of the external meatus; but they occasionally take their origin from the membrana tympani, and sometimes from the Eustachian tube. They are, as a rule, the result of long-standing otorrhcea, and the polypus makes its way out through a perforation in the membrana tympani. They vary considerably in structure, size, \&c. According to Stendener, the polypi which occur most frequently in the ear are mucous, the firm fibromata are less common, and the gelatinous myxomata the rarest. All kinds of methods have been proposed for their removal. My predecessors at St. Mary's, Toynbee and Allen, each invented an instrumentthe former the lever ring forceps, and the latter a slender three-bladed pair of forceps. Dr. Purves has also intro. duced an excellent instrument for cutting through the growth. I always use Wilde's snare, and prefer it to everg. thing else that has been suggested.

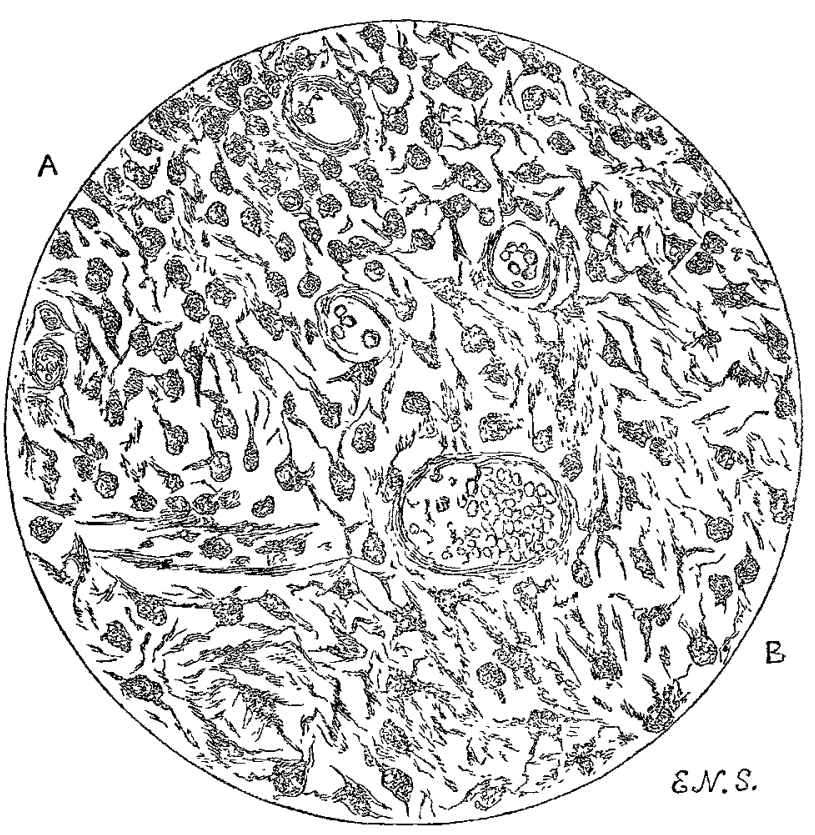

The illustration shows the microscopical appearance of the most common kind of aural polypus. I am indebted to my colleague, Dr. Shepherd, for the following notes :- "On section the growth showed the usual fibro-cellalar structure of these polypi-round, oval, and stellate cells imbedded in a delicate reticulum of fibres. In some places the latter were almost absent; in others, and apparently in the neigh. 